\title{
Interventions for return to work following work-related injuries among young adults: A systematic literature review
}

\author{
Malin K. Johansson and Ritva Rissanen* \\ Department of Global Public Health, Karolinska Institutet, Stockholm, Sweden
}

Received 15 October 2020

Accepted 2 February 2021

\begin{abstract}
.
OBJECTIVE: To provide a review of current knowledge about interventions aimed to facilitate young adults to return to work following work-related injuries.

METHODS: A systematic review of published literature from the year 2010 and onwards was conducted to identify studies examining return to work interventions for young adults (aged 19-29) following work-related injuries using PubMed and Web of Science. Two reviewers conducted the screening process and assessed the study quality using the National Heart, Lung, and Blood Institute assessment tool for Observational Cohort and Cross-Sectional studies. Due to wide heterogeneity and small number of studies retained post-screening, a descriptive summary analysis of the included studies was conducted. RESULTS: No studies were identified that focused exclusively on interventions for young adults. However, two studies, in which an age category of young adults was available, were included and assessed for quality. The study populations were primarily suffering from work-related injuries in the lower back or lower limbs. Both studies revealed that return to work interventions using a case manager coordinating and providing consultation, advice, and risk management to multidisciplinary teams was associated with lower sick leave days.

CONCLUSIONS: Despite the emerging evidence that young adults have higher rates of work-related injuries compared to older colleagues, information concerning work-related injuries and return to work interventions specifically targeting young workers is still lacking. Further research is therefore needed to develop and evaluate return to work interventions for the population of young adults.
\end{abstract}

Keywords: Occupational accident, occupational injuries, rehabilitation, return to work, young adult

\section{Introduction}

The sixth European Working Condition Survey from 2017 demonstrated that one in every four workers is exposed to work-related risks [1, 2]. Young working adults (up to the age of 29) are more likely to experience a work-related injury compared to older colleagues [3]. A systematic review published in 2019 highlighted that the high occurrence of

*Address for correspondence: Ritva Rissanen, Widerströmskahuset, Tomtebodavägen 18A, 17177 Stockholm, Sweden. Tel.: +468524833 52; E-mail: ritva.rissanen@ki.se. work-related injuries might be due to young adults being more exposed to high-risk work situations with high physical demands compared to older colleagues [4]. However, the degree of exposure to high-risk work situations varies amongst young adults, in which uneducated workers such as school dropouts have a higher degree of routine work and hard physical work [4]. Moreover, from a global perspective, sectors that attract a high number of young adults, such as construction, agriculture and manufacturing, are also sectors with a high prevalence of workrelated injuries [5]. The high rate of work-related injuries among these sectors is not only due to the 
hazardous nature of the work, but it is also associated with low staff training and a high prevalence of inexperienced, seasonal and migrant workers [5]. There are also other factors that could explain the higher rate of work-related injuries for young working adults. It could be due to a lack of work experience and knowledge about risks in the working environment, as well as young adults behaving more audaciously [6-8]. In other words, it is challenging to find a single specific reason for why work-related injuries are more commonly reported among young adults [9].

Despite the high prevalence of work-related injuries among young adults, there is a lack of research and policies regarding occupational rehabilitation and return to work (RTW) interventions for young working adults [10]. The absence of RTW interventions may prolong and increase undesirable health outcomes. Having a slow-moving progress or nonexisting RTW interventions following a work-related injury are associated with lower quality of life for the injured individual [11-13]. Previous research has mainly focused on RTW interventions including all ages with an emphasis on health promotion [14-16], preventing ill-health [17], psychosocial factors (e.g. social support) [18], and psychiatric interventions [19]. Thus, reviews that shed light on young adults work-related health are scarce [7]. Notably, the only previous review identified targeting young workers, focused on the prevention of work-related injuries, instead of how to facilitate RTW when such injuries occur [4]. The absence of intervention studies reinforces what others have described [7, 20]: RTW following work-related injuries for young adults is neglected in the rehabilitation management field. Interventions that promote well-being, rehabilitation and a successful RTW for young adults may lead to improvements in workers' health, equity, productivity and efficacy of organizations and society in general [21]. It is important to focus on young adults since they are beginners in the working life and may thereof be more vulnerable to the consequences of work injuries. In other words, by supporting and facilitating a successful RTW for young adults, an opportunity of a healthy work-life and maintained health beyond retirement age could be provided [21].

The rapidly changing demography of the work force in many countries, where young adults are being increasingly exposed to hazard events, in combination with the apparent absence of reviews examining RTW interventions for young adults, warrants a systematic condensation of the literature [7, 20]. It is important to describe what type of interventions are needed to enable RTW following work-related injuries for young adults from a global perspective, to support rehabilitation management and policies on RTW, irrespective of the origin of injury [20]. Therefore, the aim of the present study was to systematically assess and provide a review of current knowledge about interventions aimed to facilitate young adults to RTW following work-related injuries. Two research questions were included: 1) What type of work-related injuries are young adults exposed to, and 2) What, if any, type of interventions have been used to facilitate RTW for young adults?

\section{Method}

To ensure transparency and complete reporting of systematic reviews, the present study followed the Preferred Reporting Items for Systematic Reviews and Meta-Analyses (PRISMA) [22].

\subsection{Eligibility criteria}

In the present study, all types of work-related injuries were considered. A specific type of injury was therefore not used as an inclusion/exclusion criterion, except when the injury caused enough harm to make an RTW implausible. The present study defines young adults as workers in the age of 19-29 including all working arrangements. The following inclusion criteria were considered: 1) interventions of RTW status, regardless of sustained RTW, full RTW, and partial RTW, 2) inclusion of young adults aged 19-29,3) studies specified that the mechanisms leading to injury were work-related, 4) studies published in peer-reviewed journals between the years of 2010 to 2020 and 5) studies were published in English or Swedish. Lastly, all types of intervention programs that were performed with the purpose of facilitating young adults RTW following work-related injuries were included, regardless of study design. The following exclusion criteria were considered: 1) the study population was defined based on non-workrelated morbidity, 2) work-related diseases and 3) age of the study population was not defined.

\subsection{Search strategy}

Two electronic databases, PubMed and Web of Science were used to identify literature. The search was conducted in three broad categories; 1) Accidents/injuries terms, 2) Return to work/sick leave 
term, and 3) Young adults. The terms within each category were combined with the Boolean operator ('OR'). When combining the three categories with each other, the 'AND' operator was used. MeSH terms such as occupational injuries 'AND' return to work 'OR' sick leave 'AND' young adult were used. Synonyms for the MeSH terms, such as occupational accidents, sick days and young adults were also used in the three categories. In PubMed, all three categories were used (accidents/injuries terms, return to work/sick leave term, and young adults). However, in Web of Science, only two categories (accidents/injuries term and return to work/sick leave term) were used in order to get a broader scope of studies. Strategies and search terms were doublechecked and developed with a librarian at Karolinska Institutet. The initial search was conducted on the 5 th of June 2020. References in the included full-text studies were further screened to capture new studies that were not identified by the search terms. Searches were also conducted on Google Scholar to capture relevant studies that have cited the included studies, as well as to identify studies that may have published additional data on the topic.

\subsection{Assessment of relevance and inclusion}

Results from each database were merged into EndNote library and duplicates removed prior to screening. Subsequently, two independent reviewers (MKJ and RR) with expertise in injury epidemiology conducted the screening process to increase reliability of results. The reviewers conducted the identification and initial screening of all studies. The initial screening was conducted on titles and abstracts. In this phase, studies that did not include interventions were immediately removed. Studies containing RTW interventions, as well as studies containing RTW as a secondary outcome, were considered eligible and proceeded to full-text screening. An inclusive approach was used to identify true eligible studies, since an exclusive approach may erroneously exclude eligible studies. Subsequently, the two reviewers conducted the full-text screening to determine which studies fulfilled the eligibility criteria. Disagreements between reviewers were resolved through discussion.

\subsection{Data extraction}

A data extraction sheet was created to gather relevant information from each study. The sheet was pilot tested on one randomly selected study with the extraction of data conducted by the first reviewer (MKJ). Thereafter, the extracted data was cross-checked by both reviewers (MKJ and RR) and disagreements were solved through discussion. Extraction of data was conducted using full-text for the selected studies and included the following information when it was available: Source (author, journal, publication year); Research focus; Sample (age, sex, country); Design; Occupation type; Injury and mechanisms that caused the injury (type); Description of intervention (type, component); and Outcome.

\subsection{Assessment of quality}

To ascertain the validity of included studies, the two reviewers assessed the methodological quality using the National Heart, Lung, and Blood Institute assessment tool for Observational Cohort and CrossSectional studies [23]. The reviewers assessed the quality of each study individually and disagreements were resolved through discussion. The quality assessment tool includes 14 criteria (See Table 1). Each criterion was answered using the terms: included (+), not included (-), not reported (NR), cannot determine (CD), and not applicable (NA). Additionally, a quality ranking was included where each study could receive a ranking of good, fair, or poor. In general, a 'good' study has a low risk of bias, and results are considered valid. A 'fair' study has a susceptible bias, but it may not be sufficient to invalidate study results. A 'poor' study has a significant risk of bias and should be excluded. However, a 'poor' study could still be included in the review with caution if no other evidence was available [23]. The relevant quality ranking was judged by the two reviewers based on the overall validity implications from the National Heart, Lung, and Blood Institute assessment tool for Observational Cohort and Cross-Sectional studies.

\subsection{Assessment of evidence}

A descriptive summary analysis was used to identify relevant findings. The small number of studies included and the heterogeneity among participants, settings, interventions, and outcomes made a summary analysis more suitable than conducting a meta-analysis or using a qualitative synthesis. The primary reviewer (MKJ) analysed the summary in relation to the aim of the current study. A second extraction of data was conducted to summarize the main findings into the following characteristics: 
Table 1

Quality assessment criteria

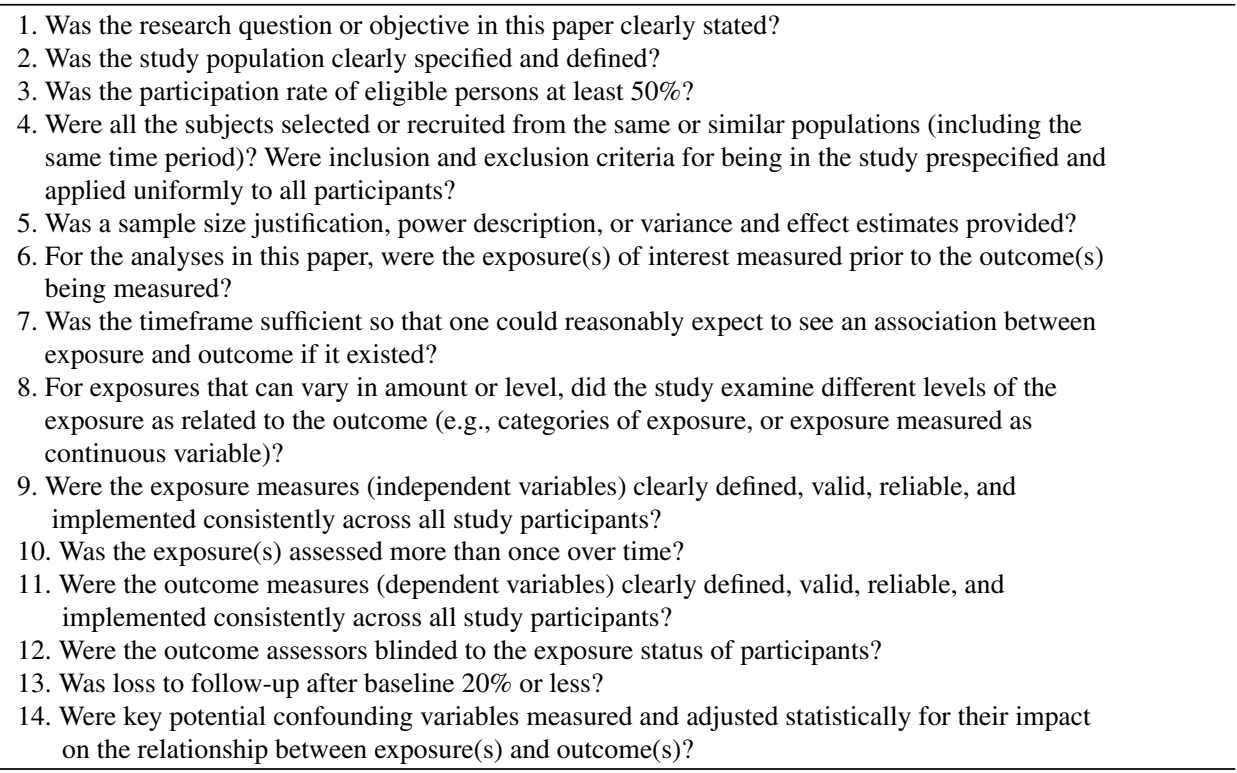

Author (Year); Country; Recruitment; Study Groups; Research aim; Type of injury; Intervention; Result; and Recommendations. Findings were presented in relation to study characteristics and the two research questions.

\section{Results}

\subsection{Study selection}

Searches of the two databases provided a total of 1,513 studies. After duplicates were removed, 1,478 studies remained. Of these, 1,402 were removed after title screening and 21 were removed after abstract screening, as they did not fulfil the eligibility criteria (e.g. did not include interventions). Thereafter, 55 studies were assessed using full-text screening and only two studies were identified as eligible for inclusion in the analysis. For more details on the screening process, see Fig. 1.

\subsection{Characteristics of included studies}

The two included studies were conducted in Hong Kong [24] and Malaysia [25]. The Hong Kong study used a cohort design with an intervention and a control group [24], while the Malaysian study used a cross-sectional design and studied different RTW phases. Neither study focused exclusively on interventions for the age category of 19-29. However, the studies did contain age categories, in which the ages 19-29 were identifiable. The study conducted in Hong Kong presented age categories that ranged up to $>65$, with the age category of $<35$ being most relevant for the purpose of the present study. However, this age group $(<35)$ had the lowest numbers of participants compared to other age categories [24]. The study conducted in Malaysia presented age categories that ranged up to $>56$, with the age category of 18 to 35 including a higher amount of participants compared to other age categories [25]. The intervention group in the Hong Kong study [24] was assigned a case manager and were also managed by a specialist at an orthopedic clinic. The intervention group was referred for early MRI to a specific multidisciplinary rehabilitation program with physical and psychosocial interventions. Meanwhile, the control group [24] received usual care provided by orthopedic doctors before being referred to other therapies within the public healthcare system. The Malaysian study [25] included a RTW program that was coordinated by case managers. The managers were responsible for the referred case from the first day until the end of the process. The RTW program included different disciplines and the process was not standardized from one case to another. The programs offered consultation, advice and risk management to an occupational rehabilitation team and were conducted at the injured worker's workplace [25]. Study participants in both 


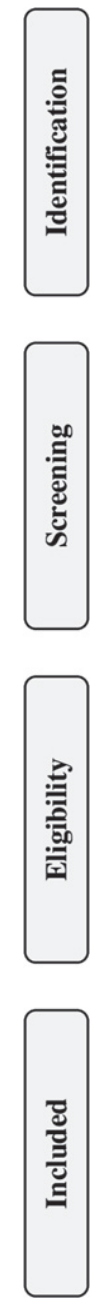

Records identified through databases Web of Science $(n=548)$ and PubMed $(\mathrm{n}=965)$ searching $(\mathrm{N}=1513)$
Additional records identified through other sources $(\mathrm{n}=0)$

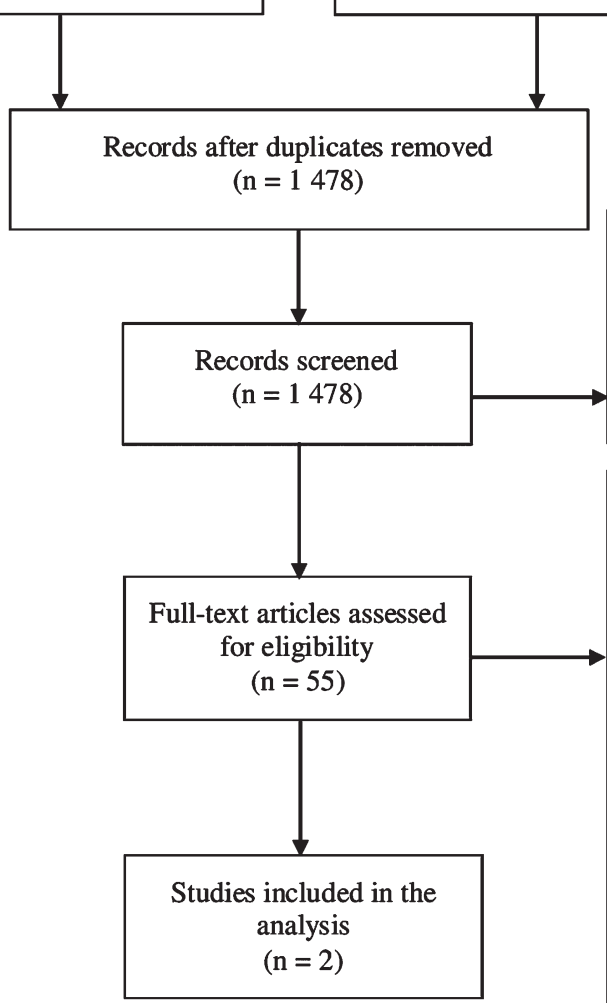

Records excluded $(n=1423)$

Exclusion based on Title $(n=1402)$

Exclusion based on Abstract $(n=21)$

Full-text articles excluded $(n=53)$

Not including interventions $(\mathrm{n}=12)$ No detailed information on age categories or intervention does not include young adults $(n=17)$

No information on reason for sick leave or sick leave was not due to a work accident $(\mathrm{n}=10)$

Study builds on a theory not relevant for RTW among young adults $(\mathrm{n}=1)$ Does not evaluate rehabilitation or RTW intervention among young adults $(n=5)$ Critical review not relevant for RTW among young adults $(n=1)$

Only includes financial aspects $(n=5)$ A case report not relevant for RTW among young adults $(\mathrm{n}=1)$

Age categories was too high for inclusion and no information if the intervention was in relation to RTW $(n=1)$

Fig. 1. Flow chart of inclusion.

studies consisted primarily of males and blue-collar workers (e.g. labor work, technical work and factory work). There were lower numbers of white-collar workers consisting of office workers, managers and professionals [24, 25]. More information regarding study characteristics is available in Table 2.

\subsection{Methodological quality assessment}

The quality assessment is summarized in Table 3. The assessment revealed that the strengths of the studies were related to the research questions and the recruitment of study participants. The Hong Kong study [24] used the same inclusion criteria for all participants and recruited participants from the orthopedic specialist out-patient clinics. The Malaysian study [25] used the same inclusion criteria for all participants and recruited the participants from the Social Security database. The assessment revealed that the Hong Kong study [24] included limitations concerning not providing information on how they initially recruited participants and if the participants adequately represented the targeted population. Neither the Hong Kong study [24], nor the Malaysian study [25] provided a description of power analysis and neither study assessed the exposure more than once. The Hong Kong study [24] provided no information concerning how RTW was measured and the Malaysian study [25] used a self-report assessment to measure RTW across the different RTW phases. The different RTW phases include 1) Off work (not at work/at work with alternative capacity), 
Table 2

Summary of characteristics of included studies

\begin{tabular}{|c|c|c|c|c|c|c|}
\hline $\begin{array}{l}\text { Author } \\
\text { (Year) } \\
\text { Country } \\
\end{array}$ & $\begin{array}{l}\text { Recruitment, } \\
\text { Population }(n), \\
\text { Sex }(n, \%)\end{array}$ & $\begin{array}{l}\text { Type of } \\
\text { Occupation }(n, \%)\end{array}$ & Research aim & Type of injury & Intervention & $\begin{array}{l}\text { Results and } \\
\text { Recommendations }\end{array}$ \\
\hline $\begin{array}{l}\text { Law et al. } \\
\text { (2016) } \\
\text { China } \\
\text { (Hong } \\
\text { Kong) }\end{array}$ & $\begin{array}{l}\text { Patients diagnosed with } \\
\text { musculoskeletal injuries } \\
\text { in lower back recruited } \\
\text { from orthopedic specialist } \\
\text { out-patient clinics during } \\
2011-2013 \text {. } \\
\text { Intervention (MORE) } \\
\text { group ( } n=139) \text { vs } \\
\text { Control group ( } n=106) \text {. } \\
\text { Intervention (MORE) } \\
\text { group consisted of males } \\
(n=98,70,5 \%) \text { and } \\
\text { females }(n=41,29.5 \%) \text {. } \\
\text { Control group consisted } \\
\text { of males }(n=74,69.8 \%) \\
\text { and females }(n=32, \\
30.2 \%) \text {. }\end{array}$ & $\begin{array}{l}\text { Intervention (MORE) group } \\
\text { consisted of white-collar } \\
\text { workers (Managers and } \\
\text { Professionals, } n=8,5.8 \%) \\
\text { Blue collar workers in the } \\
\text { Intervention (MORE) group } \\
\text { consisted of Technicians and } \\
\text { associate professionals ( } n=6, \\
4.3 \%), \text { Clerical support } \\
\text { workers ( } n=3,2.2 \%) \text {, Services } \\
\text { and sales workers }(n=40, \\
29.0 \%), \text { Skilled agricultural, } \\
\text { forestry and fishery workers } \\
(n=1,0.7 \%), \text { Craft and related } \\
\text { trades workers }(n=53,38.4 \%), \\
\text { Plant and machine operators, } \\
\text { and assemblers }(n=1,0.7 \%), \\
\text { Elementary occupations } \\
(n=26,18.8 \%), \text { Unknown } \\
(n=1,0.7 \%) \\
\text { Control group consisted of } \\
\text { white-collar workers } \\
(\text { Managers and Professionals, } \\
n=4,4.1 \%) \text {. } \\
\text { Technicians and associate } \\
\text { professionals }(n=3,3.1 \%), \\
\text { Clerical support workers }(n=1, \\
1.0 \%), \text { Services and sales } \\
\text { workers }(n=19,19.4 \%), \\
\text { Skilled agricultural, forestry } \\
\text { and fishery workers }(n=0, \\
0.0 \%), \text { Craft and related trades } \\
\text { workers }(n=47,48.0 \%), \text { Plant } \\
\text { and machine operators, and } \\
\text { assemblers }(n=2,2.0 \%), \\
\text { Elementary occupations } \\
(n=22,22.4 \%), \text { Unknown } \\
(n=8,7.5 \%) \text {. }\end{array}$ & $\begin{array}{l}\text { Evaluate the intervention } \\
\text { of the MORE program } \\
\text { on providing prompt, } \\
\text { effective, and } \\
\text { coordinated } \\
\text { patient-centred care for } \\
\text { patients with injury on } \\
\text { duty to increase the } \\
\text { chance of successful } \\
\text { return to work and } \\
\text { reduce the duration of } \\
\text { sick leave [22, p 505]. }\end{array}$ & $\begin{array}{l}\text { Work-related injury } \\
\text { to the lower back. }\end{array}$ & $\begin{array}{l}\text { MORE group: Received a } \\
\text { case manager } \\
\text { responsible for liaising } \\
\text { with medical doctors } \\
\text { and therapists, contact } \\
\text { employer and make } \\
\text { necessary arrangement } \\
\text { for injured-workers } \\
\text { RTW, give advice and } \\
\text { recommendations when } \\
\text { arranging suitable } \\
\text { duties, support and } \\
\text { monitor injured workers } \\
\text { RTW. Control group } \\
\text { received care as usual. }\end{array}$ & $\begin{array}{l}\text { MORE group promoted } \\
\text { an early RTW with } \\
\text { shorter period of sick } \\
\text { leave and shorter time } \\
\text { lag for case settlement. } \\
\text { Recommendation: Case } \\
\text { manager to improve } \\
\text { communication and } \\
\text { cooperation between } \\
\text { stakeholders, improve } \\
\text { and reduce the burden } \\
\text { of the public medical } \\
\text { service system can } \\
\text { enable faster RTW }\end{array}$ \\
\hline
\end{tabular}




\begin{tabular}{|c|c|c|c|c|c|c|}
\hline \multirow[t]{2}{*}{$\begin{array}{l}\text { Murad et al. } \\
\text { (2013) } \\
\text { Malaysia }\end{array}$} & $\begin{array}{l}\text { Participants with } \\
\text { work-related injury } \\
\text { registered in the Social } \\
\text { Security database in the } \\
\text { period of 2008-2010. }\end{array}$ & $\begin{array}{l}\text { Total consisted of Office work } \\
(n=15,14.7 \%), \text { Laboring work } \\
(n=12,11.8 \%) \text {, Technical } \\
\text { work }(n=14,13.7 \%) \text {, Factory } \\
\text { work }(n=29,28.4 \%) \text {, Other } \\
\text { (e.g. lorry drivers) }(n=32, \\
31.4 \%)\end{array}$ & $\begin{array}{l}\text { Investigate injured } \\
\text { Malaysian workers with } \\
\text { MSDs at different RTW } \\
\text { program phases based } \\
\text { on their abilities and } \\
\text { capacities [23, p. 241]. }\end{array}$ & $\begin{array}{l}\text { Work-related injury } \\
\text { located at: Head } \\
(3.9 \%), \text { Neck } \\
(2.0 \%) \text {, Trunk } \\
(24.5 \%), \text { Upper } \\
\text { Limb (18.6\%), } \\
\text { Lower Limb } \\
\text { (31.4\%) and } \\
\text { Multiple injuries } \\
\text { (19.6\%) due to } \\
\text { industrial or } \\
\text { commuting } \\
\text { accident. }\end{array}$ & $\begin{array}{l}\text { RTW program } \\
\text { coordinated by case } \\
\text { manager, involving } \\
\text { occupational therapy } \\
\text { delivered at } \\
\text { community-based level. } \\
\text { Offering consultation } \\
\text { and advice on risk } \\
\text { management program } \\
\text { to occupational } \\
\text { rehabilitation team to } \\
\text { all participants. }\end{array}$ & $\begin{array}{l}\text { Injured workers in } \\
\text { Advancement phase } \\
\text { showed lower sick leave } \\
\text { compared to Re-entry } \\
\text { and Off-work phase. }\end{array}$ \\
\hline & $\begin{array}{l}\text { Different phases included } \\
\text { Off-work }(n=30), \\
\text { Re-entry }(n=44), \\
\text { Maintenance }(n=28) \text { and } \\
\text { Advancement }(n=3) \\
\text { Total study population } \\
\text { consisted of Males } \\
(n=84,82.4 \%) \text { and } \\
\text { Females }(n=18,17.6 \%) \text {. } \\
\text { Off-work phase consisted } \\
\text { of Males }(n=25,83.3 \%) \\
\text { and Females }(n=5, \\
16.7 \%) . \\
\text { Re-entry phase consisted } \\
\text { of Males }(n=33,75.0 \%) \\
\text { and Females }(n=11, \\
25.0 \%) . \\
\text { Maintenance phase } \\
\text { consisted of Males } \\
(n=26,92.9 \%) \text { and } \\
\text { Females }(n=2,7.1 \%) .\end{array}$ & $\begin{array}{l}\text { Off-work phase consisted of } \\
\text { Office work }(n=3,10.0 \%) \text {, } \\
\text { Laboring work }(n=6,20.0 \%) \text {, } \\
\text { Technical work }(n=4,13.3 \%) \text {, } \\
\text { Factory work }(n=6,20.0 \%) \text {, } \\
\text { Other (e.g. lorry drivers) } \\
\text { ( } n=11,36.7 \%) \\
\text { Re-entry phaseconsisted of } \\
\text { Office work }(n=10,22.7 \%) \text {, } \\
\text { Laboring work }(n=4,9.1 \%) \text {, } \\
\text { Technical work }(n=4,9.1 \%) \text {, } \\
\text { Factory work }(n=12,27.3 \%) \text {, } \\
\text { Other (e.g. lorry drivers) } \\
\text { (n=14, 31.8\%) } \\
\text { Maintenance phase consisted } \\
\text { of Office work }(n=2,7.1 \%), \\
\text { Laboring work }(n=2,7.1 \%), \\
\text { Technical work }(n=6,21.4 \%) \text {, } \\
\text { Factory work }(n=11,39.3 \%), \\
\text { Other (e.g. lorry drivers) }(n=7 \text {, } \\
\text { 25.0\%) }\end{array}$ & & & & $\begin{array}{l}\text { Recommendation: Involve } \\
\text { multi-disciplinary } \\
\text { providers (e.g. } \\
\text { occupational therapists, } \\
\text { psychologists and } \\
\text { ergonomists) to enable } \\
\text { improved RTW for the } \\
\text { four phases. }\end{array}$ \\
\hline
\end{tabular}


Table 3

Quality assessment of included studies

\begin{tabular}{lcc}
\hline Criterion (C) & $\begin{array}{c}\text { Cohort } \\
\text { Design Law } \\
\text { et al. (2016) }\end{array}$ & $\begin{array}{c}\text { Cross-Sectional } \\
\text { Design Murad } \\
\text { et al. (2013) }\end{array}$ \\
\hline C1: Research question & + & + \\
C2: Study population & - & + \\
C3: Participation rate (50\%) & NR & - \\
C4: Selection of participants & + & + \\
C5: Power description & - & - \\
C6: Exposure prior to outcome & + & - \\
C7: Sufficient timeframe & + & - \\
C8: Different levels & - & + \\
$\quad$ of exposure & NR & + \\
C9: Definition of exposure & - & - \\
C10: Assessing exposure & - & - \\
C11: Definition of outcome & - & - \\
C12: Blinding & NR & NA \\
C13: Follow-up & - & - \\
C14: Confounding variables & - & \\
\hline
\end{tabular}

+: included, -: not included, NA: not applicable, NR: not reported.

2) Re-entry (starting back at work), 3) Maintenance (working at previous capacity), 4) and Advancement (improve work responsibility). These phases are considered non-linear, meaning that an individual can loop back to previous phases during the process [26]. No outcome assessor in neither study was blinded since physicians had diagnosed the participants with a work-related injury prior to the start of the studies. Follow-up was not provided in the study conducted in Hong Kong [24], and it was not applicable for the Malaysian study [25] due to its cross-sectional design. Neither study controlled nor adjusted for confounding variables. These overall methodological uncertainties, as well as potential sources of bias, lead to the two studies being assessed as of poor to moderate quality.

\subsection{Type of work-related injury}

The included studies did not address the type of work-related injuries that were most common for each age category, or specifically for young adults. The overall results showed that the type of workrelated injuries identified in the two studies were mainly related to musculoskeletal injuries [24, 25]. The study conducted in Hong Kong investigated only work-related injuries that occurred in the lower back [24]. The study conducted in Malaysia included work-related injuries located on the head, neck, trunk, upper limb, lower limb, or on multiple locations of the body [25]. The maintenance group (working at previous capacity) in the Malaysian study had the highest proportion of individuals aged 18-35, with the most common work-related injury located on the lower limb [25].

\subsection{Interventions to facilitate RTW after work-related injuries}

In the two included studies, the RTW interventions did not specifically target young adults, seeing as the studies did not have a tailored intervention for each age category. Rather, all participants in all age categories received the same treatment. The overall results showed that the common denominator for a successful RTW was a case manager that coordinated and provided consultation, advice and risk management to multidisciplinary teams (e.g. occupational therapists, psychologist and ergonomics) [24, 25]. The study conducted in Hong Kong showed a higher success rate for RTW and lower sick leave days for the intervention group compared to the control group. A specific emphasis was on early interventions to enable a faster RTW [24]. In view of the fact that the maintenance group in the Malaysian study had the highest proportion of participants aged 18-35, they were of primary interest in the present review. The maintenance group showed lower sick leave days (including all types of injuries) compared to the off-work and the re-entry phase groups [25]. However, the overall findings of the study showed that the lowest number of sick leave days belonged to an Advancement RTW phase group, when compared to three other RTW phases [25].

\section{Discussion}

To our knowledge, the present review is the first study that systematically provides a review of interventions facilitating young adults RTW following work-related injuries. The results of this review indicate that interventions targeting young adults RTW are lacking. We were only able to identify two articles that defined the study population based on age categories, however, neither of these studies included interventions that specifically targeted young adults. Rather the interventions were general for all of the age groups of the study populations. Moreover, the same issue regarding age categories were present in relation to the types of injuries the participants were exposed to. In the included studies, work-related injuries occurred mainly in the lower back or lower limb. Therefore, it is difficult to identify the types of work-related injuries that mainly belonged to the 
specific age-groups. Finally, the findings suggested that having a case manager coordinating and providing consultation might be helpful in facilitating a successful RTW. However, this conclusion is not specific for the age category of young adults.

\subsection{Work-related injuries for young adults}

Supported by previous studies within the field [2, 7], findings in the present study indicated that musculoskeletal injuries may be a frequent work-related injury among young adults. However, while there is consistency with previous findings concerning musculoskeletal injuries, this type of injury may not exclusively apply to young adults. Instead, the lack of eligible studies limits the ability to draw conclusions regarding work-related injuries among young adults.

For this review, the aim was to find literature on interventions targeting RTW for young adults following a work-related injury, which means that previous studies focusing exclusively on the type of injuries young adults are exposed to were excluded. Thereby, previous studies targeting work-related injuries among young adults exist, but were not eligible for inclusion in this review due to the lack of inclusion of interventions for the age group. However, taking previous studies into consideration, there seems to be no single specific work-injury that is more related to young working adults. Instead, previous research emphasizes that the type of occupation and working contract [6, 27], educational level [4], psychosocial and physical maturity levels, as well as experience [6-8] are factors that may influence the type of work-related injury young adults are exposed to. For example, statistics from Sweden show that injuries such as knife-cuts from handheld tools and machines are common for young working adults in construction and metal industries [2]. Meanwhile, in the trade and restaurant industry work-related injuries for young working adults are related to heat, fire, welding, cold, electricity, explosions and serious burns from boiling water or hot oil [2]. In other words, the example shows that types of work-related injury that young adults obtain can be dependent on the type of occupation.

It is also necessary to point out that the term young adults may also lead to differences in results. Thus, there are different ways to classify workers as young, which means that the cut-off age is different depending on studies. This lack of clear-cut definitions for young adults may introduce problems for current and future research, since one may not know for sure what type of work-related injuries young adults are exposed to. However, establishing consensus concerning age cut-off in studies is difficult since some individuals may, due to educational differences, be introduced to the labor market in older age.

\subsection{Return to work interventions for young adults}

The present study shows that there is a shortage of available literature on interventions to facilitate young adults RTW following work-related injuries. The paucity of scientific information on young adults in the included studies, as well as the overall lack of eligible intervention studies, limits the ability to draw conclusions regarding RTW interventions for young adults. Thus, the low number of eligible studies suggests that this field is either under-researched or limited with publication bias. Taking previous studies into consideration, the included studies were not based exclusively on young adults and work-related injuries. However, the studies may be relevant when discussing interventions for young adults and in planning interventions studies targeting young adults.

A Danish randomized controlled trial evaluated the effect of an RTW-program for workers on longterm sickness absence among three municipalities using RTW coordinators and multidisciplinary teams. Their findings indicated that contextual factors (e.g. sociodemographic differences) are of major importance for success or failure in RTW interventions [28]. A Finnish study published in 2014 examined the effects of new legislation on partial sickness benefit to reduce withdrawal of workers from the labor market. Their results indicate that the legislation has the potential to increase work participation for workers on long-term sickness absence [29]. Another randomized controlled pilot study investigated if an early intervention would lead to an early RTW. The results of the study, however, did find that an early intervention caused major constraints for both the experienced physiotherapist that examined patients and the overall clinic. Focus should instead be on the design of the RTW interventions and how it could be less time consuming [30]. The overall diversity and complexity of RTW interventions also suggests that there may be no single, optimal RTW approach that can be applied across contexts and populations. It is also noteworthy to highlight that it is unclear what successful RTW means for young adults. Rehabilitation plans used for older workers should perhaps not be used for young adults as well, since the majority of 
young adults are employed within precarious work such as temporary and part-time work $[4,20]$. Therefore, similar rehabilitation plans might not suit young workers, especially since precarious work is related to unstable employment and dangerous working conditions $[4,20]$. Furthermore, RTW for young adults can be compromised if rehabilitation lasts longer than the work contracts, since it can affect the sense of work security [7]. Lastly, young adults may not necessarily respond in the same way to an established rehabilitation plan compared to older colleagues due to generational and social differences (e.g. socioeconomic status). A need exists for further intervention studies to try and understand and assess the effectiveness of different RTW interventions for young adults following work-related injuries.

Concerning the methodological quality of the included studies, the two studies being of poor to moderate quality. These overall methodological uncertainties mean that the findings in the two included studies should be interpret with caution. For instance, the two studies were carried out in uppermiddle income countries, which might be indicative of the progress of RTW interventions carried out in these countries. Hence, these results might not be representative for high- or low-income countries with other RTW settings and should therefore be interpreted with caution.

\subsection{Methodological considerations}

One of the main strengths of this review was the double reviewing of studies, which increased the reliability of results. In other words, the double reviewing increased the possibility that no studies were missed. Another strength of the present study was that it followed the guideline PRISMA statement for reporting systematic reviews and it assessed the methodological quality using the National Heart, Lung, and Blood Institute assessment tool for Observational Cohort and Cross-Sectional studies. Using these guidelines increased the reliability of this review since it provided guidance on what to report and include in a systematic review to make it possible to replicate the review. Lastly, the present study is the first known systematic literature overview to focus specifically on RTW for young adults. A literature review covering a global perspective was conducted, providing the opportunity to compare studies on young working adults living with diverse working conditions. The broad inclusion made it possible to attain a global indication of interventions that are mostly relevant to
RTW. Thereby, the review provides information that can hopefully be used to fill the knowledge gap that exists for interventions aimed at facilitating young adults RTW.

Despite our best efforts, there were several limitations to the review. Since the search only included two databases a possibility exists that some studies were missed. However, it is considered unlikely that studies were missed since no additional records were found from references of the included studies. Efforts were also made to control for publication bias by searching registered protocols on the Clinical Trials Registry Platform. However, none were found, which may suggest that there is limited publication bias present. Detecting selection bias by scanning databases relies on the possibility of studies being registered as protocols and later being omitted for publication. Unfortunately, it is not common practice in epidemiological research to publish study protocols [31, 32]. It was also considered of little relevance to produce Egger-based publication bias analysis because of the limited number of included studies. Thus, the variety of age groups, injuries, and interventions between studies, as well as the low number of included studies, prevented the authors from conducting a meta-analysis.

The low number of scientific studies on young adults shows that there is a need for more studies that focus exclusively on young adults. Hence, future studies should include either young adults or specific groups of young adults (e.g. uneducated workers such as school dropouts) to avoid categorizing into groups using only age as a factor. The results also show that some occupations and genders are more studied than others (e.g. blue-collar workers and males). Therefore, future studies should look at populations from a wider variety of different occupations, especially where young adults are overrepresented (e.g. restaurant industry), as well as to target occupations including a higher proportion of females. At the same time, it is important to emphasize that young adults are comprised of a heterogeneous group and that their vulnerability could be highly contextual. Thus, important stakeholders (e.g. researcher, practitioners and politicians) should try to capture this complexity when initiating interventions to facilitate young adults RTW following work-related injuries. To sum up, future research should focus on RTW interventions for young adults, whilst taking into consideration that young adults are a heterogeneous group. Thereof, different interventions should be studied for different groups of young adults. 


\section{Conclusions}

The current study is the first literature review that examines interventions aimed to facilitate young adults return to work following work-related injuries, however, we were not able to draw any conclusion regarding interventions specifically targeting young adult RTW since no studies focusing with a specific focus on young adults were identified. Since the results in the two included studies were not presented in terms of age categories, it is hard to generalize results to the specific age group being investigated in the present study. Hence, interpretation of the results from this review should be done in light of the understanding that young adults are underrepresented in the two included studies. Therefore, we urge researchers to develop and evaluate RTW interventions for the population of young adults, especially considering the surge in the prevalence of work-related injuries among young adults. The evidence offered in this review can be used as a starting point to drive research into a currently understudied area.

\section{Authors contributions}

MKJ and RR developed the study and its design. MKJ conducted the search in the bibliographic databases with the support from librarians at Karolinska Institute. MKJ and RR participated in the selection of studies. MKJ extracted the data from the selected studies and analyzed the results. MKJ drafted the manuscript with the support and feedback from RR. All authors have read and approved the final manuscript.

\section{Conflict of interest}

The authors declare that there is no conflict of interest.

\section{Ethical approval}

No ethical assessment and informed consent were required. No primary data collecting was undertaken.

\section{Funding}

This work was supported by AFA Försäkringar, grant number 180273 .

\section{References}

[1] AFA Försäkring. Allvarliga arbetsskador och långvarig sjukfrånvaro [Internet]. Stockholm: AFA Försäkring; 2018.

[2] AFA Försäkring. Allvarliga arbetsolyckor och långvarig sjukfrånvaro bland unga [Internet]. Stockholm: AFA försäkring; 2016.

[3] Eurofound. Sixth European Working Conditions Survey Overview report (2017 update). Luxembourg: Publications Office of the European Union; 2017.

[4] Hanvold TN, Kines P, Nykanen M, Thomee S, Holte KA, Vuori J, et al. Occupational Safety and Health Among Young Workers in the Nordic Countries: A Systematic Literature Review. Saf Health Work. 2019;10(1):3-20.

[5] ILO. Safety and health at work: Why are youth at risk? [internet]. Genève; 2018. Available from: https://www.ilo. org/infostories/en-GB/Stories/safety-health/youth\#intro.

[6] Salminen S. Have young workers more injuries than older ones? An international literature review. J Safety Res. 2004;35(5):513-21.

[7] Laberge M, Ledoux E. Occupational health and safety issues affecting young workers: a literature review. Work. 2011;39(3):215-32.

[8] Breslin FC, Smith P. Age-related differences in work injuries: a multivariate, population-based study. Am J Ind Med. 2005;48(1):50-6.

[9] Arbetsmiljöverket. Arbetsmiljöstatisitk Rapport 2019:01. Arbetsskador 2018. Occupational accidents and workrelated diseases. Stockholm: Arbetsmiljöverket; 2018.

[10] EU-OSHA. Rehabilitation and return to work: Analysis report on EU and Member States policies, strategies and programmes. Luxembourg: Publications Office of the European Union, 2016; 2016.

[11] Moergeli H, Wittmann L, Schnyder U. Quality of life after traumatic injury: a latent trajectory modeling approach. Psychother Psychosom. 2012;81(5):305-11.

[12] Hou WH, Sheu CF, Liang HW, Hsieh CL, Lee Y, Chuang HY, et al. Trajectories and predictors of return to work after traumatic limb injury-a 2-year follow-up study. Scand J Work Environ Health. 2012;38(5):456-66.

[13] Hou WH, Liang HW, Sheu CF, Hsieh CL, Chuang HY. Return to work and quality of life in workers with traumatic limb injuries: a 2-year repeated-measurements study. Arch Phys Med Rehabil. 2013;94(4):703-10.

[14] Crawford JO, Graveling RA, Cowie HA, Dixon K. The health safety and health promotion needs of older workers. Occup Med (Lond). 2010;60(3):184-92.

[15] Lopez Bueno R, Casajus Mallen JA, Garatachea Vallejo N. Physical activity as a tool to reduce disease-related work absenteeism in sedentary employees: A systematic review. Rev Esp Salud Publica. 2018;92.

[16] Steenstra I, Cullen K, Irvin E, Van Eerd D, Alavinia M, Beaton D, et al. A systematic review of interventions to promote work participation in older workers. J Saf Res. 2017;60:93-102.

[17] Andersen JH, Malmros P, Ebbehoej NE, Flachs EM, Bengtsen E, Bonde JP. Systematic literature review on the effects of occupational safety and health $(\mathrm{OSH})$ interventions at the workplace. Scand J Work Environ Health. 2019;45(2): 103-13.

[18] White C, Green RA, Ferguson S, Anderson SL, Howe C, Sun J, et al. The Influence of Social Support and Social Integration Factors on Return to Work Outcomes for Individuals with Work-Related Injuries: A Systematic Review. J Occup Rehabil. 2019;29(3):636-59. 
[19] Lin KH, Lin KY, Siu KC. Systematic review: effect of psychiatric symptoms on return to work after occupational injury. Occup Med-Oxf. 2016;66(7):514-21.

[20] EU-OSHA. OSH in figures: Young workers - Facts and figures. Brussels: European Agency for Safety and Health at Work; 2007.

[21] Cancelliere C, Donovan J, Stochkendahl MJ, Biscardi M, Ammendolia C, Myburgh C, et al. Factors affecting return to work after injury or illness: best evidence synthesis of systematic reviews. Chiropr Man Therap. 2016;24(1):32.

[22] Liberati A, Altman DG, Tetzlaff J, Mulrow C, Gotzsche PC, Ioannidis JP, et al. The PRISMA statement for reporting systematic reviews and meta-analyses of studies that evaluate health care interventions: explanation and elaboration. PLoS Med. 2009;6(7).

[23] NIH. Study Quality Assessment Tools. Quality Assessment Tool for Observational Cohort and Cross-Sectional Studies [Internet]. Bethesda: NIH; [date unknown] [cited 2020 4 may]. Available from: https://www.nhlbi.nih.gov/healthtopics/study-quality-assessment-tools.

[24] Law SW, Szeto GP, Chau WW, Chan C, Kwok AW, Lai HS, et al. Multi-disciplinary Orthopaedics Rehabilitation Empowerment (MORE) program: A new standard of care for injured workers in Hong Kong. J Back Musculoskelet Rehabil. 2016;29(3):503-13.

[25] Murad MS, O’Brien L, Farnworth L, Chien CW. Health status of people with work-related musculoskeletal disorders in return to work programs: a Malaysian study. Occup Ther Health Care. 2013;27(3):238-55.
[26] Young AE, Roessler RT, Wasiak R, McPherson KM, van Poppel MN, Anema JR. A developmental conceptualization of return to work. J Occup Rehabil. 2005;15(4):557-68.

[27] Bravo G, Viviani C, Lavallière M, Arezes P, Martínez M, Dianat I, et al. Do older workers suffer more workplace injuries? A Systematic Review. International journal of occupational safety and ergonomics. 2020(just-accepted): $1-56$.

[28] Poulsen OM, Aust B, Bjorner JB, Rugulies R, Hansen JV, Tverborgvik T, et al. Effect of the Danish return-to-work program on long-term sickness absence: results from a randomized controlled trial in three municipalities. Scand J Work Environ Health. 2014;40(1):47-56.

[29] Kausto J, Viikari-Juntura E, Virta LJ, Gould R, Koskinen A, Solovieva S. Effectiveness of new legislation on partial sickness benefit on work participation: a quasi-experiment in Finland. BMJ Open. 2014;4(12):e006685.

[30] Norbye AD, Omdal AV, Nygaard ME, Romild U, Eldoen G, Midgard R. Do Patients With Chronic Low Back Pain Benefit From Early Intervention Regarding Absence From Work?: A Randomized, Controlled, Single-Center Pilot Study. Spine (Phila Pa 1976). 2016;41(21).

[31] Trinh QD, Sun M. Statistical analysis plans in observational research. JAMA. 2013;309(1):32.

[32] Thomas L, Peterson ED. The value of statistical analysis plans in observational research: defining high-quality research from the start. JAMA. 2012;308(8):773-4. 